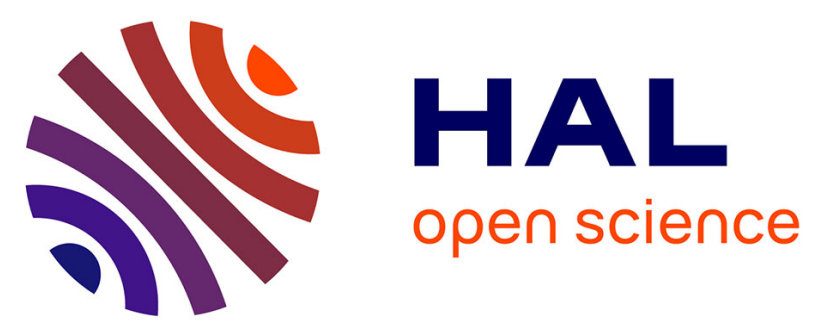

\title{
Interaction of redox probes and ferrocene-labelled peptides with lipid bilayers observed at lipid bilayer-modified electrodes
}

Dejan Segan, George Stanley, Pierluca Messina, Jean Marie Swiecicki, Kieu Ngo, Vincent Vivier, Olivier Buriez, Eric Labbe

\section{To cite this version:}

Dejan Segan, George Stanley, Pierluca Messina, Jean Marie Swiecicki, Kieu Ngo, et al.. Interaction of redox probes and ferrocene-labelled peptides with lipid bilayers observed at lipid bilayer-modified electrodes. ChemElectroChem, 2021, 8, pp.2556-2563. 10.1002/celc.202100501 . hal-03276973

\section{HAL Id: hal-03276973 \\ https://hal.sorbonne-universite.fr/hal-03276973}

Submitted on 2 Jul 2021

HAL is a multi-disciplinary open access archive for the deposit and dissemination of scientific research documents, whether they are published or not. The documents may come from teaching and research institutions in France or abroad, or from public or private research centers.
L'archive ouverte pluridisciplinaire HAL, est destinée au dépôt et à la diffusion de documents scientifiques de niveau recherche, publiés ou non, émanant des établissements d'enseignement et de recherche français ou étrangers, des laboratoires publics ou privés. 


\title{
Interaction of redox probes and ferrocene-labelled peptides with lipid bilayers observed at lipid bilayer-modified electrodes
}

Dejan Segan, ${ }^{[a]}$ George Stanley, ${ }^{[b]}$ Pierluca Messina ${ }^{[a]}$, Jean-Marie Swiecicki, ${ }^{[b]}$ Kieu Ngo, ${ }^{[c]}$ Vincent Vivier, ${ }^{[c]}$ Olivier Buriez, ${ }^{[a]}$ and Eric Labbé ${ }^{[a]}$ *

[a] Dr Pierluca Messina, Dr Dejan Segan, Dr Olivier Buriez, Pr Eric Labbé PASTEUR, Département de chimie, École Normale Supérieure, PSL University, Sorbonne Université, CNRS, 75005 Paris, France

[b] Dr. George Stanley, Dr.Jean Marie Swiecicki Laboratoire des biomolécules (LBM), Département de chimie, Sorbonne Université, École normale supérieure, PSL University, Sorbonne Université, CNRS, 75005 Paris, France

[c] Dr. Kieu Ngo and Dr. Vincent Vivier Laboratoire Interfaces et Systèmes Électrochimiques (LISE) Sorbonne Université, CNRS, 75005 Paris, France

\begin{abstract}
Glassy carbon electrodes (GCE) modified by a bilayer of phospholipids (BLM) have been used to monitor the passage of redox probes and ferrocene-labelled peptides across lipid membranes of an anionic (DOPG) or a zwitterionic (globally neutral DPhPC) phospholipid. The gel-phase neutral DPhPC showed a strong association with neutral probes like ferrocene methanol but expelled positively or negatively charged species, as observed on cyclic voltammograms. Anionic DOPG underwent a strong electrostatic interaction with the positively charged hexaamine ruthenium(III) complex, leading to aggregates that caused swelling and destructuration of the BLM. With positively charged ferrocenetagged peptides, DOPG-modified GCE allowed the observation of cyclic voltammograms exhibiting both a potential shift with respect to bare GCE and increased peak intensity, accounting for the slow but favored partition of the peptides between the BLM and the solution.
\end{abstract}

Keywords

redox probes; peptides, Supported Bilayer Lipid Membrane; Electrochemical Impedance Spectroscopy; cyclic voltammetry 


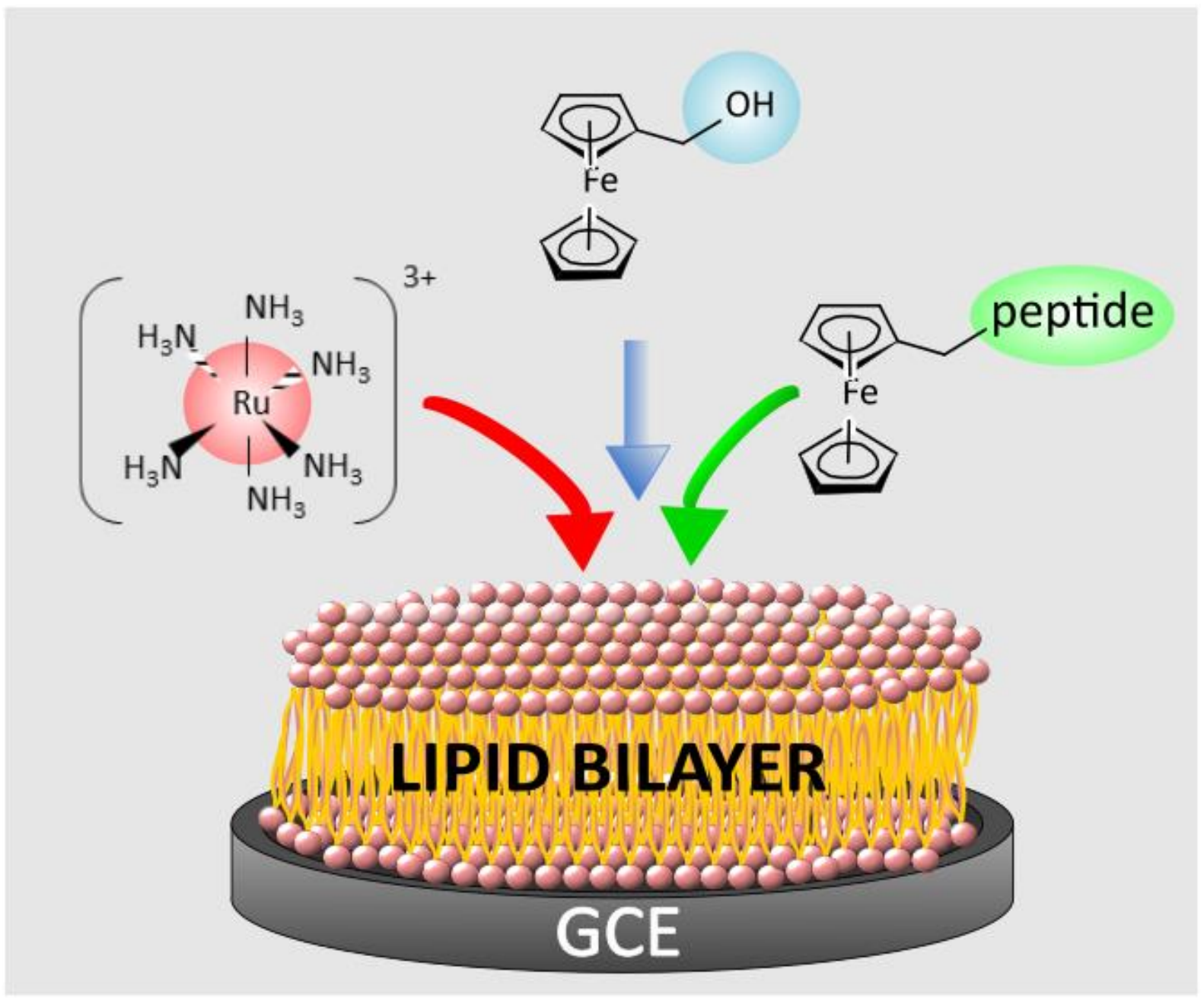

Redox probes and ferrocene-labelled peptides have been studied by cyclic voltammetry (CV) at lipid bilayer modified glassy carbon electrode (GCE). Gel ordered phosphatidylcholine lipids only interact with neutral probes, expelling the cations. With liquid disordered negatively charged phosphoglycerol lipids, electrostatic interactions with the probes are observed and the CVs obtained for ferrocene-tagged peptides highlight a mixed thin layer and diffusion behavior. 


\section{Introduction}

Plasma membranes are the interfaces which regulate the flux of ions and molecules getting in and out of living cells. Transmembrane trafficking refers not only to the regular metabolism of cells, but also to the delivery of drugs or pathogens ${ }^{[1-2]}$, hence rising up research topics focusing on the mechanisms of membrane crossing. Molecular transport across membranes is generally classified into passive modes (i.e. energy-independent processes following the concentration and/or electrical field gradients) and active modes (which require energy and specific regulation) ${ }^{[3]}$. The amphiphile nature of the phospholipids composing the membranes increases the complexity of the trafficking pathways, especially when it concerns the translocation of ionic species through the hydrophobic region of lipid bilayers. The specific example of the internalization of cell penetrating peptides (CPPs) in purely lipidic liposomes, which matches the features and definition of a passive transport, has been the subject of a number of explorations and interpretations in the last two decades, as reported in early ${ }^{[4]}$, recent ${ }^{[5-7]}$ or very recent ${ }^{[8]}$ reviews.

The experimental strategies aimed at exploring and quantifying the passage of peptides across lipid membranes rely on several techniques. These methods may be classified according to the possibility to use label-free peptides (e.g. X-ray ${ }^{[9]}$ or neutron diffraction ${ }^{[10]}$, Differential Scanning calorimetry ${ }^{[11]}$, Infrared spectroscopy MALDI-ToF MS ${ }^{[12-13]}$ ), and also according to the dynamic information they provide (e.g. $\mathrm{NMR}^{[14]}$ ). Fluorescence-based methods ${ }^{[15-17]}$, which require the functionalization by fluorophores display a unique sensitivity in the micromolar concentration range. The reader is encouraged to consult the paper by Avci et al. for a comprehensive review ${ }^{[18]}$. However, some methods either require expert knowledge or setups (NMR) or present some drawbacks associated to the chemical quenching of non-internalized peptides ${ }^{[19-20]}$. Electrochemical techniques provide a variety of time-resolved approaches namely through impedance spectroscopy, amperometry or voltammetry. In 2014, we developed an electrochemical method to monitor and quantify the passage of small molecules across suspended BLMs formed by patch-clamp techniques ${ }^{[21]}$, a strategy allowing the characterization of fluxes across membranes in contact with solutions at both sides. Since CPP concentrations lie in the 10-100 $\mu \mathrm{M}$ range in vivo, the concentration gradient across a suspended membrane is too low to generate a significant (electrochemically detectable) efflux of CPP, considering a fraction of the CPPs may remain bound to the membrane. With this respect, we have implemented electrochemical methods to explore the permeation and fluxes of model redox probes at bilipidic membranes (BLMs) deposited at the surface of glassy carbon electrodes (GCE). The interactions of CPPs with supported membranes have already been investigated by Quartz Crystal Microbalance with Dissipation monitoring (QCM-D) ${ }^{[22]}$ or by Scanning Electrochemical Microscopy (SECM) ${ }^{[23]}$. Supported BLMs may afford an adequate electrochemical interface to explore the passage of redox species from 
the solution to the electrode surface (and vice versa) across the membrane. In 2012, we established that a cationic CPP could be modified with a redox probe such as ferrocene so as to allow its electrochemical detection ${ }^{[24]}$. In this work, ferrocene-labelled peptides could be detected at a micromolar concentration, exhibiting the characteristic voltammetric wave of the ferrocene probe. In these conditions, the faradaic signal displayed a poor resolution due to the small diffusion rate of the peptide. Two other strategies have been investigated to improve the faradaic signal resolution. The first one used avidin/biotin recognition to preconcentrate the CPP at the electrode surface, but the ferrocene probe showed irreversible voltammograms under these conditions. A second strategy consisted in modifying the electrode with a cation-exchange polymer ${ }^{[25]}$, which allowed a rapid preconcentration of the cationic CPP at the electrode surface. This led to a very good signal-to-noise ratio and ensured stability of the redox wave. In 2015, the preparation as well as the electrochemical detection of a CPP composed of nine arginines and tagged with a ferrocenyl unit (noted as Fc-R9 in Figure 1) at a carbon fiber electrode immersed in a micro-volume suspended water droplet was successfully investigated. Accordingly, a well-defined sigmoidal voltammogram was obtained at slow scan rate in the presence of micromolar concentration of the Fc-R9 peptide ${ }^{[26]}$.

Herein, we have first investigated the permeation of classical redox probes (hexaamineruthenium(III) and ferrocene methanol) by electrochemical impedance spectroscopy and cyclic voltammetry at glassy carbon electrodes modified with two phospholipids of interest (diphytanoyl phosphatidylcholine (DPhPC, zwitterionic and in gel ordered phase at all temperatures ${ }^{[27]}$ ) and dioleyl phosphatidyl glycerol (DOPG, anionic and in liquid disordered phase above $\left.-18^{\circ} \mathrm{C}^{[28]}\right)$ ) for the study of the interactions between membranes and peptides. Then, we have explored the behavior of ferrocene-labelled peptides classified as penetrating and non-penetrating in former studies at DOPG-modified GCE. The lipids, probes and ferrocene-tagged peptides explored in this study are represented in Figure 1. 


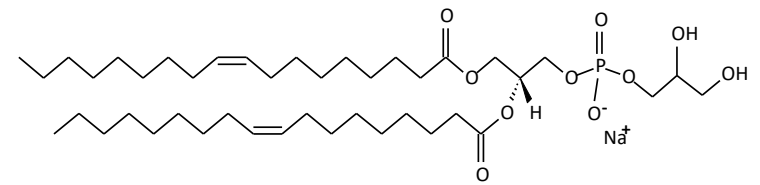

DOPG = 1,2-dioleoyl-sn-glycero-3-phospho-(1'-rac-glycerol)

$$
(\underbrace{\mathrm{Ru}_{3} \mathrm{~N}}_{\mathrm{NH}_{3}} \stackrel{\mathrm{NH}_{3}}{\mathrm{NH}_{3}})^{3+}
$$

$\mathrm{Ru}\left(\mathrm{NH}_{3}\right)_{6}{ }^{3+}$

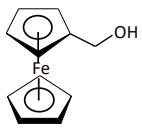

Fc-MeOH<smiles>CC(C)CCCC(C)CCCC(C)CCCC(C)CCCC(C)CCCC(C)CC(=O)OC[C@@H](COP(=O)([O-])OCC[N+](C)(C)C)OC(=O)CC(C)CCCC(C)C</smiles>

DPhPC = 1,2-diphytanoyl-sn-glycero-3-phosphocholine

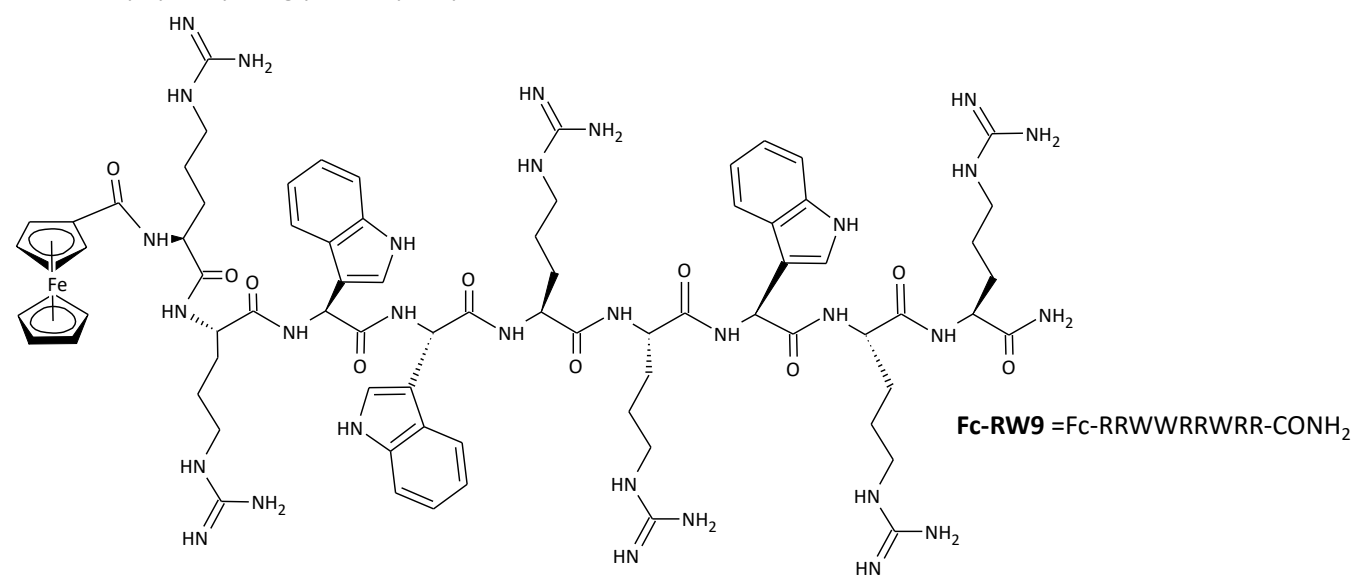<smiles></smiles><smiles>CC(C)C[C@H](NC(=O)[C@H](C)NC(=O)CNC(=O)[C@H](CCCCN)NC(=O)[C@H](CCCCNC(=N)N)NC(=O)[C@H](C)NC(=O)[C@H](Cc1ccccc1)NC(=O)[C@H](CCCNC(=N)N)NC(=O)c1ccccc1)C(N)=O</smiles><smiles>CC(CCCNC(=N)N)C(=O)N[C@@H](CCC(N)=O)C(=O)N[C@@H](CCCCN)C(=O)N[C@@H](CC(N)=O)C(=O)N[C@H](C(N)=O)C(C)C</smiles>

Fc-pKCi $=$ Fc-RFARKGALRQKNV-CONH

Figure 1

Structure of the lipids and probes used in this work 


\section{Experimental}

a. Chemicals

Diphytanoyl phosphatidylcholine (DPhPC) and dioleyl phosphatidyl glycerol (DOPG) were purchased from Avanti Lipids, dissolved in chloroform to obtain $2 \mathrm{~mL}$ solutions at $2.5 \mathrm{mg} / \mathrm{mL}$ and stored under argon in a freezer at $-20^{\circ} \mathrm{C}$. These solutions were directly used for the formation of BLMs on GCE (see below). Potassium hexacynaoferrate $\mathrm{K}_{3} \mathrm{Fe}(\mathrm{CN})_{6}$; ferrocene methanol Fc-MeOH and hexaamineruthenium(III) chloride $\mathrm{Ru}\left(\mathrm{NH}_{3}\right)_{6} \mathrm{Cl}_{3}$ were purchased from Sigma Aldrich and used as received. $\mathrm{PKCi}, \mathrm{R} 9$ and $\mathrm{RW} 9$ were synthesized on an $\mathrm{MBHA}$ resin $\left(0.54 \mathrm{mmol}^{-\mathrm{g}^{-1}}\right)$ via standard Boc solid phase peptide synthesis ${ }^{[29]}$. Once the peptide synthesis was complete, the $\mathrm{N}$-terminal Boc protecting group was removed with Trifluoroacetic acid (TFA). The resin was washed with dichloromethane, Nmethyl-2-pyrrolidone (NMP) and neutralized with $10 \%$ (v/v) N,N-diisopropylethylamine (DIPEA, AnalaR NORMAPUR, Carlo Erba) in NMP and finally washed with NMP. The peptide still on resin was reacted for $30 \mathrm{~min}$ with a solution of ferrocene carboxylic acid (5 eq., Sigma-Aldrich) in the presence of Hexafluorophosphate Benzotriazole Tetramethyl Uronium (HBTU, 4.5 eq., Iris Biotech GmbH) and DIPEA ( 10 eq.) in NMP. The peptidyl-resin was finally washed with NMP, methanol and dried overnight under vacuum before HF cleavage. Crude peptides were purified by RP-HPLC and their identity was confirmed by MALDI-ToF MS.

b. Electrode and film procedures

The cyclic voltammograms and electrochemical impedance spectra were recorded using an Autolab (PGSTAT 20) potentiostat (Ferrocene methanol and hexaamineruthenium probes) or an Ametek Princeton Applied Research 2273 Potentiostat (ferrocene-labelled peptides).

GCE preparation and lipid film formation: The GC Electrode was thoroughly polished with 2400 \& 4000 Mecaprex polishing paper using alumina slurry (on 4000), rinsed with ethanol and water, then ultrasonicated. This electrode was left in buffer solution overnight. GCE was polarized at $1.5 \mathrm{~V}$ vs $\mathrm{Ag} / \mathrm{AgCl}$ in a $0.1 \mathrm{M} \mathrm{KCl}$ solution for 180 seconds, according to a carbon surface conditioning procedure inspired from the work by Wang et al. ${ }^{[30-31]}$. The oxidation of GC surface by electrochemical polarization and its characterization have been described in aqueous solutions of variable $\mathrm{pH}$ and produce a $\mathrm{pH}$ dependent distribution of surface group ${ }^{[32-34]}$. Although originally described in alkaline solutions, the 
polarization of the electrode in aqueous $\mathrm{KCl}$ afforded a GC oxidized surface prone to immobilize lipid layers, as already observed ${ }^{[35]}$ and described hereafter. The electrode was removed, rinsed with $\mathrm{H}_{2} \mathrm{O}$ and dried under argon. Lipid solutions ( $6 \mu \mathrm{L}$ at $2.5 \mathrm{mg} / \mathrm{mL}$ in chloroform) were deposited onto the electrode from a $10 \mu \mathrm{L}$ glass syringe. Due to the hydrophilic polarized surface of the electrode and the amphiphilic character of the phospholipids, the molecules spontaneously assemble into a lipid film structured as a bilayer covering the electrode surface ${ }^{[35]}$. The electrode was dried under argon and then added to the electrochemical cell containing $1.85 \mathrm{~mL}$ of aqueous solution " $\mathrm{S}$ " composed of $\mathrm{D}-(+)-$ glucose $(0.32 \mathrm{M}), \mathrm{NaCl}(0.15 \mathrm{M})$ and $\mathrm{NaN}_{3}(4.6 \mathrm{mM})$ - that composition of the solution was originally envisioned to form lipid films via LUV deposition / opening on GCE, method finally discarded because the lipid coverage appeared too heterogeneous and poorly reproducible-. The probes and peptides were introduced as $0.15 \mathrm{~mL}$ of $1 \mathrm{mM}$ aqueous solution in the cell already containing $1.85 \mathrm{~mL}$ of solution "S", resulting in $75 \mu \mathrm{M}$ solutions in contact with the BLM-modified GCE.

\section{Results and discussion}

\subsection{Lipid film characterization}

We first used a qualitative approach to assess the formation of a lipid thin-film on the electrode, and checked the electrochemical response of hexacyanoferrate solutions before and after formation of the lipid film. Figure 2 shows the cyclic voltammograms (CVs) of $\mathrm{Fe}(\mathrm{CN})_{6}{ }^{3-}$ either at neutral (DPhPC), anionic (DOPG) or mixed (DPhPC:DOPG 70:30) lipidic films. The quasi reversible monoelectronic reduction of $\mathrm{Fe}(\mathrm{CN})_{6}{ }^{3-}$ is observed at $0.05 \mathrm{~V}$ vs. $\mathrm{Ag} / \mathrm{AgCl}$ at unmodified GCE electrode. For BLM-modified electrodes, the absence of faradaic response revealed a near-complete blocking of the electrode surface, as previously described for glassy carbon electrodes modified with lipid bilayers ${ }^{[30,35]}$. For DPhPC-modified GCE (Fig 2A), a low amplitude S-shape CV still appeared, mostly accounting for micro-defects in the GCE coverage which may be interpreted as the faradaic signal of $\mathrm{Fe}(\mathrm{CN})_{6}{ }^{3-}$ at an array of independent micrometer-size electrodes.

Electrochemical Impedance Spectroscopy (EIS) was also performed on BLM-modified GCE. After recording the impedance of a bare GCE electrode in aqueous $0.1 \mathrm{M} \mathrm{NaCl}$ (without redox probe), the BLM modified GCE were examined in the same medium. The Nyquist representations of DPhPC- and DOPG-modified GCE are shown in Figure 3, the Bode plots are in the SI. 

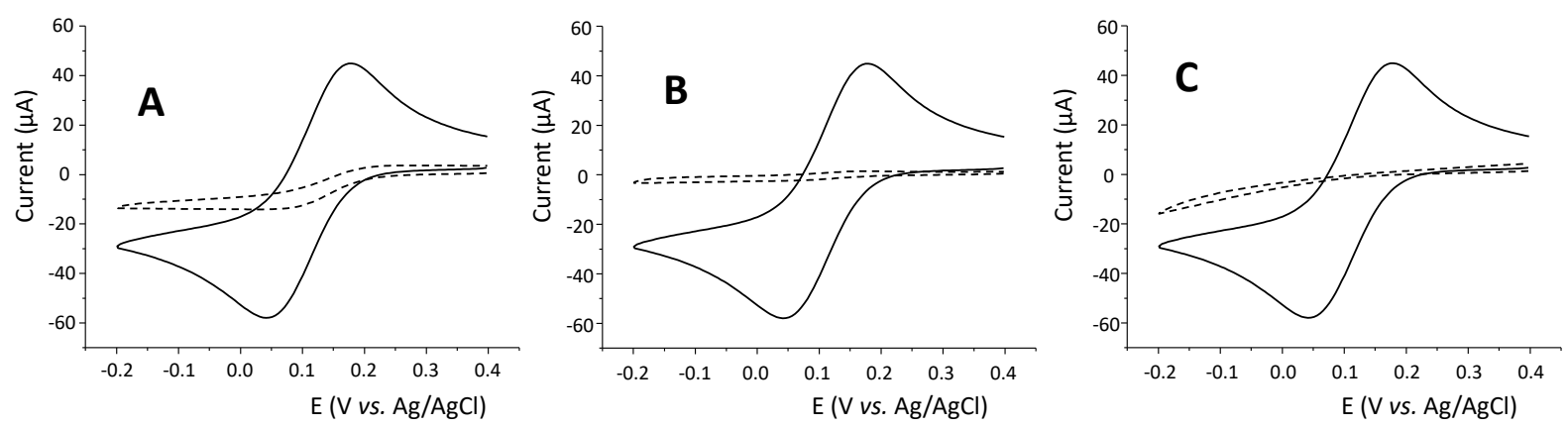

Figure 2

$\mathrm{CVs}$ of $\mathrm{K}_{3} \mathrm{Fe}(\mathrm{CN})_{6} 5 \mathrm{mM}$ in solution " $\mathrm{S}$ " at bare GCE (solid line) and BLM-modified GCE (dashed line) at $40 \mathrm{mV} \cdot \mathrm{s}^{-1}$. A: BLM = pure DPhPC ; B: BLM = pure DOPG ; C: BLM = DPhPC:DOPG 70:30 mass ratio. Scan rate: 0.1 V.s $s^{-1}$ for all CVs

For both bare and modified electrodes, a non-ideal capacitive behavior is observed in the whole frequency domain. In the case of BLM modified GCE, the electrode-solution interface can be represented by a Constant Phase Element (CPE) accounting for the electrical properties of the membrane in series with the double layer capacitance and the electrolyte resistance. In the case of bare GCE, the electrochemical response consisted in the double layer contribution (which also shows a non-ideal behavior) and the electrolyte resistance, only. Assuming a surface distribution of the interface properties (due to current and potential distribution of the electrified interface), the capacity accounting for this non-ideal behavior can be estimated from Brug's formula ${ }^{[36]}$ :

$$
C_{B}=Q^{1 / \alpha}\left(\frac{R_{e}+R_{t}}{R_{e} R_{t}}\right)^{\frac{\alpha-1}{\alpha}}
$$

where $R_{e}$ and $R_{t}$ are electrolyte resistance and transfer resistance, respectively.

For the experiments presented in Fig. 3 , it is obvious that the $R_{t}$ values are several orders of magnitude larger than the electrolyte resistance, thus leading to the simplified formula

$$
C_{B}=Q^{1 / \alpha}\left(R_{e}\right)^{\frac{1-\alpha}{\alpha}}
$$

For the bare GCE (Fig. 3.A), $\alpha=0.82, Q=1.1110^{-6} \Omega^{-1} \mathrm{~s}^{0.82}$, leading to a capacitance value of $2.2 \mu \mathrm{F}$ $\mathrm{cm}^{-2}$, which is in fair agreement with the double layer value expected at a CGE.

For modified GCE, $\alpha=0.73$ and $Q=8.810^{-7} \Omega^{-1} s^{0.73}$ was obtained for DPhPC and $\alpha=0.72, Q=9.310^{-}$ ${ }^{7} \Omega^{-1} \mathrm{~s}^{0.72}$ for DOPG. In both cases, the evaluation of the capacitance leads to $C_{B}=0.46 \mu \mathrm{F} \mathrm{cm}{ }^{-2}$. 
Assuming a model of a plane capacitor, $C_{B}$ may also be expressed as $C_{B}=\varepsilon \varepsilon^{\circ} / d$ where $\varepsilon^{\circ}$ is the vacuum permittivity $\left(\varepsilon^{\circ}=8.8510^{-14} \mathrm{~F} \mathrm{~cm}^{-1}\right), \varepsilon$ the dielectric constant of the medium ( $\varepsilon=2.05$ for apolar hydrocarbon chain ${ }^{[37]}$ ) and $d$ the capacitor thickness. With this model, $d$ is estimated at $3.9 \mathrm{~nm}$, a value consistent with the thickness of a bilayer of lipid molecules ${ }^{[35]}$. It is also interesting to note that this value is obtained by making the assumption that the capacity of the double layer which forms is negligible compared to the capacity of the bilayer. If we assume that the double layer is of the order of $5 \mu \mathrm{F} \mathrm{cm}{ }^{-2}$ on the bilayer, then the error made is an underestimation of about $7.5 \%$ of the thickness (3.6 nm).
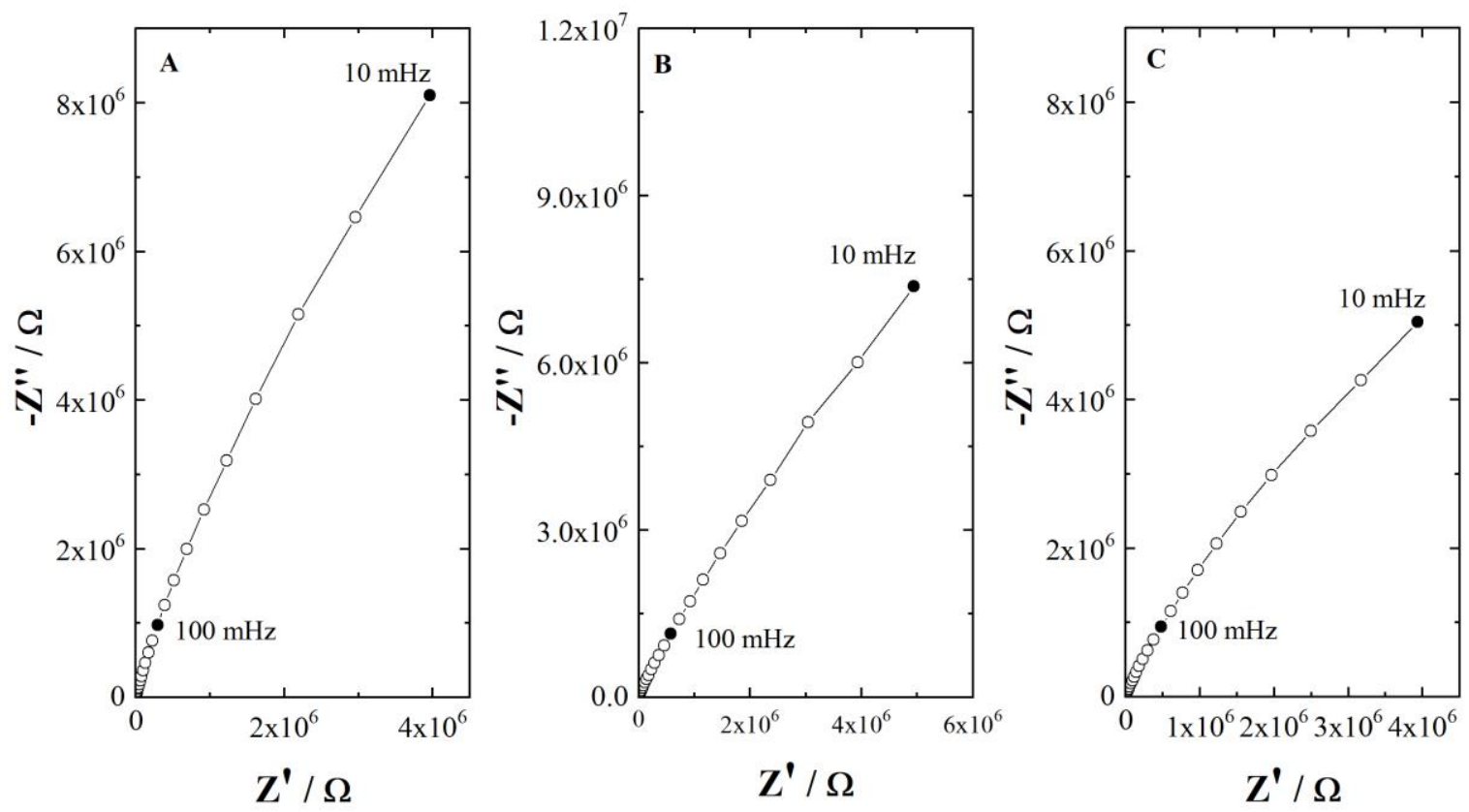

Figure 3

Nyquist plots of bare GCE (A), and DPhPC (B) and DOPG (C) modified GCE in aqueous $0.1 \mathrm{M} \mathrm{NaCl}$. Applied potential $0.25 \mathrm{~V}$ vs. $\mathrm{Ag} / \mathrm{AgCl}$ (perturbation $10 \mathrm{mV}_{\mathrm{rms}}$ )

\subsection{Electrochemical behavior of redox probes at BLM-modified electrodes}

We have selected both neutral and cationic redox probes in order to study the behavior of positively charged species - a general feature of peptides - with neutral or anionic phospholipids. Accordingly, $\mathrm{Ru}\left(\mathrm{NH}_{3}\right)_{6}{ }^{3+}$ and ferrocene methanol Fc-MeOH were used to carry out cyclic voltammetry on various proportion of DPhPC and DOPG BLMs immobilized on GC electrodes. The corresponding CVs are presented in Figure 4. 
The cationic $\mathrm{Ru}\left(\mathrm{NH}_{3}\right)_{6}{ }^{3+}$ probe reduces at $-0.22 \mathrm{~V} / \mathrm{Ag} / \mathrm{AgCl}$ at bare $\mathrm{GC}$ electrode (Fig. $\left.4 \mathrm{~A}\right)$. The formation of a lipid film dramatically affects the CVs: at DPhPC-GCE interface, the reduction of the ruthenium probe is no longer observed, a behavior that can be ascribed to the blocking of the electrode surface by the DPhPC BLM. Upon introduction of an increasing amount of DOPG in the lipid film, a reduction peak of $\mathrm{Ru}\left(\mathrm{NH}_{3}\right)_{6}{ }^{3+}$ is recovered, but at more negative potential values. This observation indicates that i) DOPG-enriched lipid films appear permeable to cationic probes and ii) $\mathrm{Ru}\left(\mathrm{NH}_{3}\right)_{6}{ }^{3+}$ is stabilized by the DOPG environment (it is reduced at more negative potential values), most likely through electrostatic association between the cationic probe and the anionic phospholipid. If successive scans are performed with the DOPG-GCE in the same conditions, the CVs show a dramatic current increase and both reduction and backward oxidation peaks of the ruthenium complex adopt symmetrical shapes, together with a decrease of the anodic to cathodic peak potential separation (Fig. 4B).
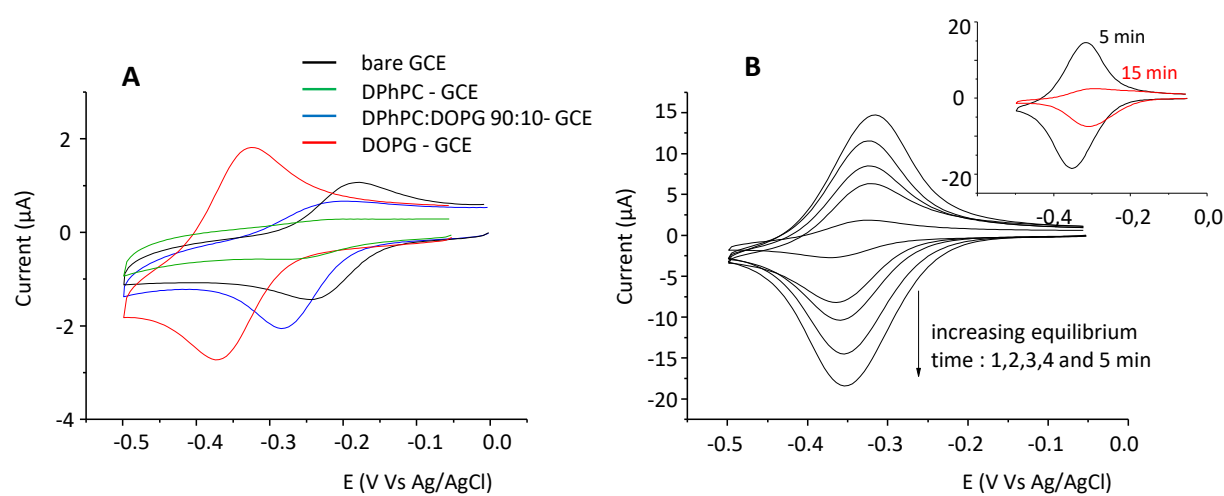

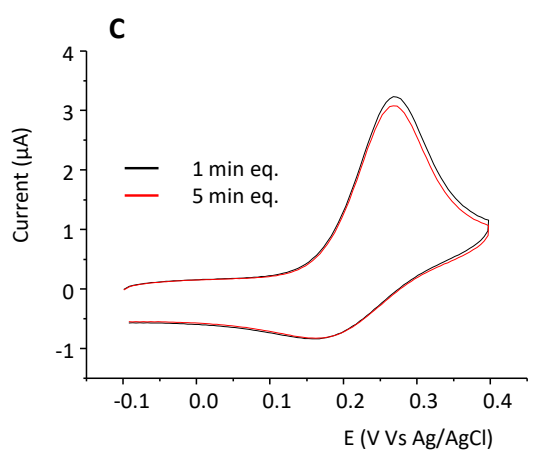

$100 \% \mathrm{DPhPC}$

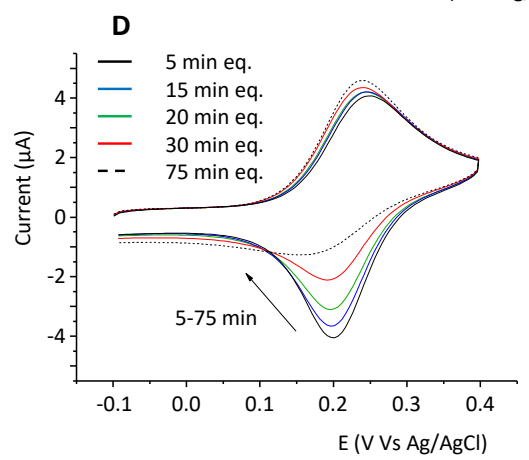

50:50 DPhPC:DOPG

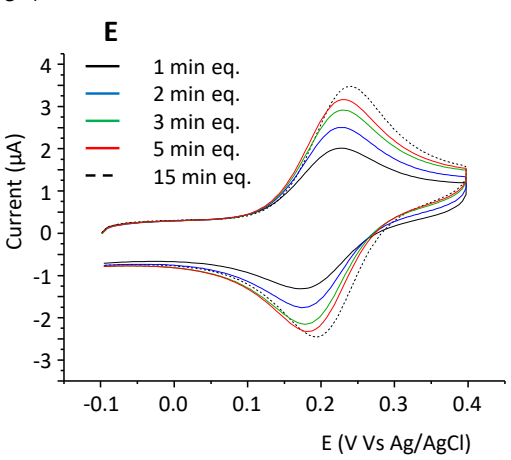

$100 \%$ DOPG

Figure 4

A : CVs of $\mathrm{Ru}\left(\mathrm{NH}_{3}\right)_{6}{ }^{3+} 75 \mu \mathrm{M}$ in solution $\mathbf{S}$ at various BLM-modified GCE . B : successive CVs of $\mathrm{Ru}\left(\mathrm{NH}_{3}\right)_{6}{ }^{3+} 75 \mu \mathrm{M}$ after a 1-5 min equilibrium time in buffer $\mathbf{S}$ at DOPG-modified GCE - inset: overlay of CVs after 5 and 15 min equilibrium time. C, D, E : CVs of Fc-MeOH $75 \mu \mathrm{M}$ at various BLM-modified GCE and after different equilibrium time in solution S. C : DPhPC-GCE. D : DPhPC:DOPG 50:50-GCE. E : 
For pure DOPG-modified electrodes, $\mathrm{Ru}\left(\mathrm{NH}_{3}\right)_{6}{ }^{3+}$ behaves like a redox species that accumulates in a thin layer grafted to the electrode. Actually, the integration of the reduction peak displayed at the scan obtained after 5 min equilibrium in Fig. 4B yields an apparent electrode surface coverage of $3.310^{-9}$ mol.cm ${ }^{-2}$, a value six times larger than the one observed for close packed ferrocene functionalized selfassembled monolayers at gold electrodes $\left(5.10^{-10} \mathrm{~mol}^{\mathrm{cm}} \mathrm{cm}^{-2}\right)^{[38]}$, the probe no longer acting as a dilute species in a solvent/phase. Such an accumulation of the cationic probe within the anionic DOPG under our conditions progressively leads to the swelling of the lipid membrane, as observed in the inset of Fig. $4 \mathrm{~B}$ where the CV (in red) obtained after $15 \mathrm{~min}$ features both a decreased peak current and a positive potential shift for the Ru'l'/Ru" redox process. Finally, the evolution of the CVs is consistent with an initial strong interaction between the ruthenium complex and the DOPG film, leading to a progressive destructuration of the lipid film after 5 minutes.

The electrochemical response of Fc-MeOH probed at DOPG- and DPhPC-modified GC electrodes is shown on Figures 4C-E. Two very different voltammograms are obtained on pure DPhPC-GCE and pure DOPG-GCE. The oxidation of Fc-MeOH on DPhPC-GCE (Fig 4C) displays a mixed diffusional-adsorbed shape peak during the forward scan and a much smaller reduction peak during the backward scan. The neutral Fc-MeOH probe oxidizes to a cationic ferricinium which is expelled from the neutral DPhPC film, resulting in an asymmetric $\mathrm{CV}$. Thus, only a small fraction of $\mathrm{Fc}^{+}-\mathrm{MeOH}$ electrogenerated during the forward scan remains in the vicinity of the GCE surface to be reduced during the subsequent cathodic scan. At DOPG-GCE, Fc-MeOH exhibits symmetrical CVs, with peak currents increasing with the equilibrium time (Fig 4E). This observation suggests that i) Fc-MeOH progressively accumulates in the DOPG film and ii) $\mathrm{Fc}^{+}-\mathrm{MeOH}$ produced during the forward scan is not expelled from the lipid film and reduces along a mostly diffusional process. At mixed DPhPC:DOPG 50:50 films (Fig. 4D), the initial voltammograms of Fc-MeOH essentially resemble those obtained at pure DOPG-GCE. Increasing the equilibrium time results in a progressive evolution of the CVs towards pure "DPhPC-like" CVs, with asymmetric shapes. The voltammograms in Fig. 4D indicate that Fc-MeOH initially associates to DOPG but the lipid film most likely undergoes slow demixing and the final CVs feature the oxidation of Fc$\mathrm{MeOH}$ at DPhPC-enriched phases within the lipid film.

The electrochemical behavior of $\mathrm{Fe}(\mathrm{CN})_{6}{ }^{3-}, \mathrm{Ru}\left(\mathrm{NH}_{3}\right)_{6}{ }^{3+}$ and $\mathrm{Fc}-\mathrm{MeOH}$ at $\mathrm{BLM}$-modified electrodes finally reveals that DPhPC remains impermeable to ions, whatever the sign of their charge. Actually, a cationic species generated at the GC-DPhPC interface is expelled from the film, while cations and anions in solution do not produce any faradaic signal, a proof of the blocking character of the DPhPC film. DOPG films strongly associate with cationic species, that interaction even leading to a swelling of the lipid film. The apparent thickness of the BLM-modified electrodes has been estimated from the capacitance obtained from EIS experiments for $\mathrm{Ru}\left(\mathrm{NH}_{3}\right)_{6}{ }^{3+}$ and $\mathrm{Fc}-\mathrm{MeOH}$ probes as a function of the potential 
applied to GCE (Figure 5). It shows that most lipid-probe combinations afford dimensionally stable lipid films, except the DOPG- $\mathrm{Ru}\left(\mathrm{NH}_{3}\right)_{6}{ }^{3+}$ couple, which exhibits a dramatic increase of the thickness upon reaching potential values that allow reduction of the ruthenium precursor. The polarization of the DOPG-modified GCE at potential values allowing the reduction of $\mathrm{Ru}\left(\mathrm{NH}_{3}\right)_{6}{ }^{3+}$ for $70-90$ seconds (duration required for the recording of EIS data) appears to considerably affect the DOPG film structure and apparent thickness (Fig. 5). Since the positive charge borne by the ruthenium complex may only decrease upon reduction, the destructuration of the DOPG film may result from the large partition constant of $\mathrm{Ru}\left(\mathrm{NH}_{3}\right)_{6}{ }^{3+}$ between the solution and the DOPG film that could form bulky Ru/DOPG aggregates, leaving the GCE coated with a fraction of disorganized and multilayered DOPG molecules. Actually, the swelling and denaturation of BLMs upon incorporation of small molecules like chloroform $^{[39]}$ or benzene ${ }^{[40]}$ has been described and even explains the mode of action of several anesthetics ${ }^{[41]}$. A recent work by Kim et al explored the interaction of the Green Malachite cation with anionic DPPG films at the air-water interface and the authors described the adsorption of the cation forming a highly packed condensed phase near the lipid headgroup region ${ }^{[42]}$. Therefore, an adsorption of $\mathrm{Ru}\left(\mathrm{NH}_{3}\right)_{6}{ }^{3+}$ to the anionic heads of DOPG could take place as a first step, followed by a reorganization of the ruthenium-DOPG adduct, to the detriment of the lipid film.

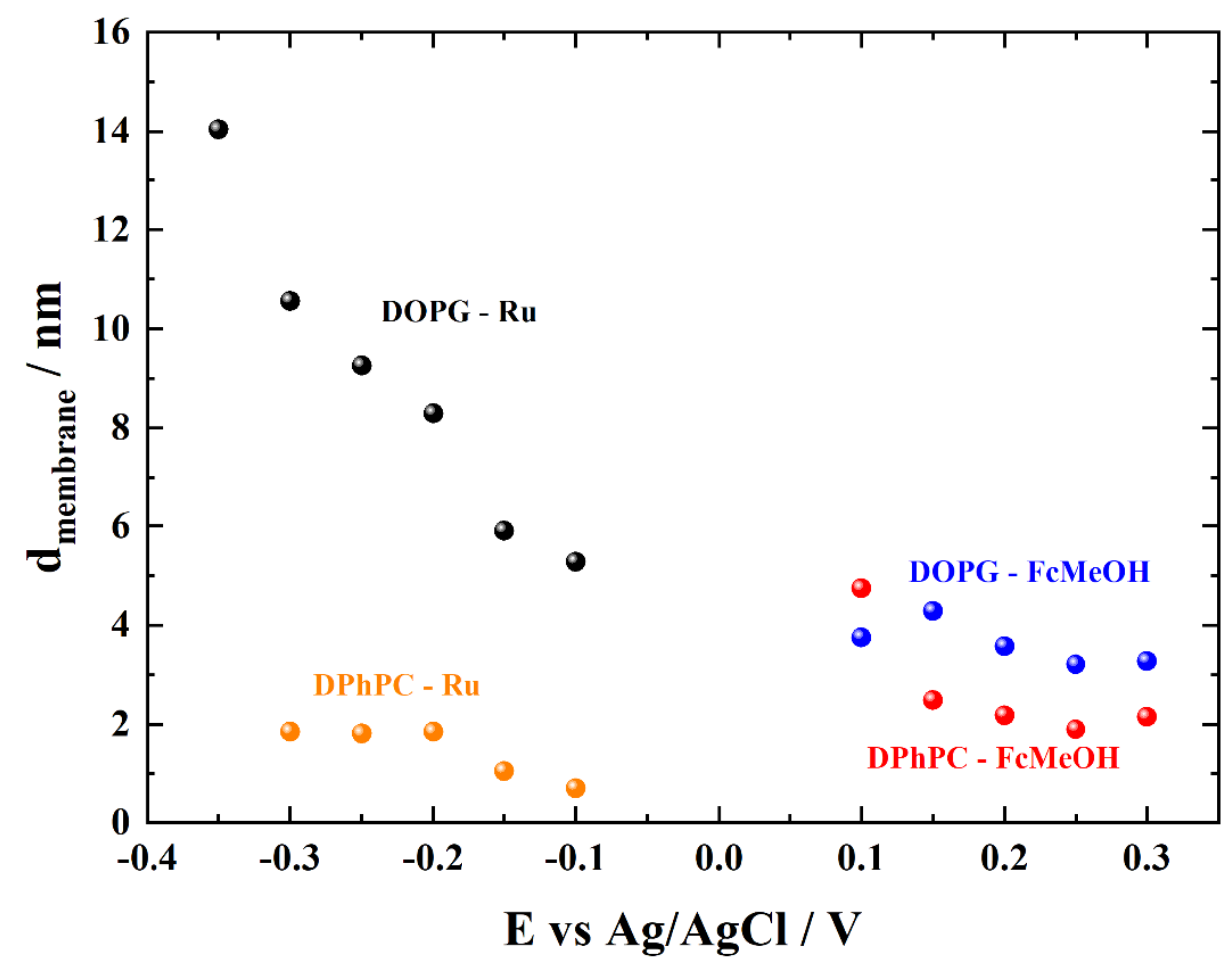

Figure 5

Apparent thickness of DPhPC-GCE and DOPG-GCE reconstructed from EIS experiments as a function of the probe and the potential applied to GCE. 
Considering the electrochemical behavior of electrogenerated $\mathrm{Fc}^{+}-\mathrm{MeOH}$ at GCE coated with neutral gel phase lipid bilayer (Fig 4C), polycationic peptides are expected to be expelled from the lipid film, a feature also observed with ferrocene and ferrociphenols at a similar phosphatidycholine BLMs (1,2dimyristoyl-sn-glycero-3-phosphocholine DMPC) ${ }^{[35]}$. That is why we focused on the interactions of peptides with the negatively charged DOPG films. We have explored the electrochemical response of bare-GCE and DOPG-modified GCE towards ferrocene-functionalized peptides, introduced at biologically-relevant concentrations, i.e. in the micromolar range. Our objective was the characterization of interactions between the negatively charged heads of the phospholipids and the positively charged peptides. $\mathrm{Fc}-\mathrm{pKCi}(\mathrm{pKCi}=$ protein kinase $\mathrm{C}$ inhibitor) represents a non-penetrating peptide, Fc-R9 is "non-amphipathic" (random coil secondary structure) and Fc-RW9 is "secondary amphipathic" (alpha helix conformation with both cationic and hydrophobic residues ${ }^{[7]}$ ). Their primary structure is displayed in Fig. 1. The cyclic voltammograms of Fc-pKCi , Fc-RW9 and Fc-R9 are presented in Figure 6.
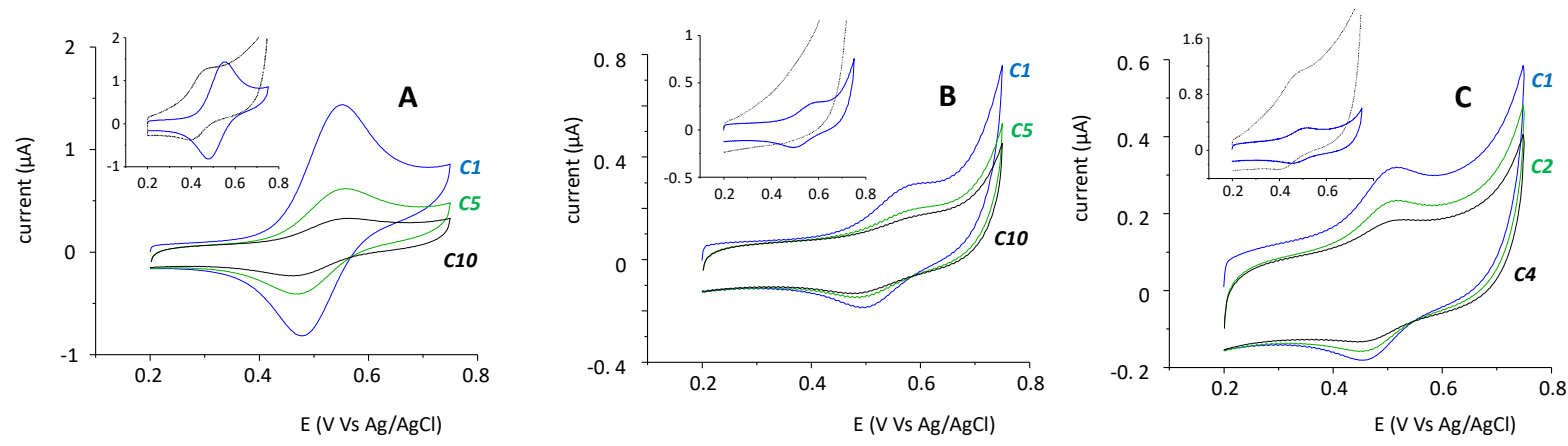

Figure 6

Multi-CVs of Fc-labelled peptides (75 $\mu \mathrm{M}$ in solution S) at DOPG-modified GCE. Blue line: CV obtained after 20 min equilibrium time in solution, $1^{\text {st }}$ cycle (C1). The other cycles selected (green and black lines) are reported on the graphs. Insets: Overlay of the CVs obtained after 20 min equilibrium in solution S at bare-GCE (black line) and DOPG-modified GCE (blue line, same as main graph). (A) FcpKCi. (B) Fc-RW9. (C) Fc-R9. Scan rate: $0.04 \mathrm{~V} \mathrm{~s}^{-1}$ for all CVs

After a period of contact between the solution and the modified electrode, Fc-pKCi displays a welldefined reversible CV at DOPG-GCE (Fig. 6A, cycle C1). The comparison of the CVs obtained at DOPG- 
modified and unmodified GCE (inset in Fig 6A) shows that the ferrocene probe is oxidized at more positive potential values at DOPG-GCE and that the peak current increases at DOPG-GCE, revealing a strong interaction between $\mathrm{Fc}-\mathrm{pKCi}$ and the lipid film. Actually, the higher oxidation potential value accounts for a stabilization of the ferrocene environment by DOPG, while the higher peak current suggests that the peptide accumulates in the lipid film. A continuous cycling results in a decrease of the peak current (Fig. 6A, cycles $\mathrm{C5}$ and $\mathrm{C10}$ ), showing that potential cycling progressively leads to a depletion of Fc-pKCi in the lipid film. Allowing the DOPG-modified GCE to re-equilibrate for 20 minutes with the $75 \mu \mathrm{M}$ solution of Fc-pKCi results in recovering the original blue CV (not shown), confirming that Fc-pKCi undergoes a slow partition equilibrium between the solution and the DOPG film. Fc-RW9 and Fc-R9 peptides exhibit a similar electrochemical behavior at bare-GCE and DOPG-GCE, although less pronounced than in the case of Fc-pKCi (Figs. 6B and 6C).

The peak current increase at DOPG-GCE (compared to bare GCE), mostly observed for Fc-pKCi and FcRW9, shows that the positively charged peptides associate with the DOPG film. A strictly electrostatic association between the polycationic peptides and the phosphate-based anionic heads at the DOPG/solution interface would not give rise to a faradaic response, as commented above for the redox probes that cannot penetrate the lipid layer. The shape of the CVs in Fig. 6A resemble those of free diffusing electroactive species and display an anionic-to-cathodic peak separation of 70 to $90 \mathrm{mV}$ (cycles 1 and 5 respectively). The motion of electroactive probes like $\mathrm{Ru}\left(\mathrm{NH}_{3}\right)_{6}{ }^{3+}$ in polymer films attached to the electrode has been described namely in the case of ionomeric polymers ${ }^{[43-45]}$. In such polymer films, two transport regimes are observed : at high scan rates (short time scales), the peaks on the CVs exhibit a dependence on $\mathrm{v}^{1 / 2}$ (square root of the scan rate), accounting for a diffusioncontrolled motion within the film, and a dependence on $\mathrm{v}$ at lower scan rates, ascribed to the total reduction or oxidation of the species in a thin layer attached to the electrode. The junction between the two regimes allows an estimation of the apparent diffusion coefficients $D_{\text {app }}$ within the film from an expression derived from the mean square motion of species by diffusion, $\delta=\left(2 \mathrm{D}_{\text {app }} \mathrm{t}\right)^{1 / 2}{ }^{[46]}$. This method is well adapted to the description of the motion of species essentially located in the film (i.e. with high partition coefficients between the film and the solution). The fluid/dynamic character of DOPG at room temperature (DOPG is in fluid disordered phase) also makes it distinct from structurally "frozen" polymer films. In the present study, the attempts to establish a clear dependence of the peak currents with the scan rate have failed. Considering that very low scan rates in cyclic voltammetry allow a partial re-equilibration of the peptide concentration in the DOPG phase, the peak currents tend to represent a mixed contribution of the peptides already bound to DOPG and peptides present in solution. Instead, we envision in our future prospects to use other electrochemical techniques to estimate both the partition coefficient and $D_{a p p}$, namely voltammetry at rotating disk electrodes as 
described by Compton et al. for thin films ${ }^{[47]}$. In the lipid film, one must consider that the cationic peptides most likely recruit DOPG molecules to allow a globally neutral entity to reach the GCE surface. Finally, the CVs in Figure 6 recorded at DOPG-GCE do not represent the oxidation of a species strictly immobilized within the 4 nanometer-thick lipid bilayer (the anodic and cathodic peaks exhibit a 70-90 $\mathrm{mV}$ peak-to-peak separation). If the CVs in Figure 6 clearly underline the interaction between the cationic peptide and the anionic lipid film, their diffusional reversible shape excludes the occurrence of an oxidation restricted to the fraction of peptide already associated to the lipid film.

One could expect cationic peptides to exhibit an electrochemical behavior at DOPG-GCE similar (and even amplified with respect to the multiple cationic sites) to the one observed for $\mathrm{Ru}\left(\mathrm{NH}_{3}\right)_{6}{ }^{3+}$. Several recent studies have focused on the association of model cationic peptides, mostly polyarginine $\left(\operatorname{Arg}_{8}\right.$ and $\mathrm{Arg}_{9}$ ) and polylysine (Lys $\mathrm{s}_{8}$ and $\mathrm{Ly}_{9}$ ) and bilayers of anionic phosphoglycerol (PG) lipids (DMPG and POPG) through the combination of multiple experimental techniques (fluorescence, QCM-D, second harmonic generation spectroscopy, nanoplasmonic sensing) and molecular dynamics simulation ${ }^{[48-49]}$. Although possessing the same cationic charge at physiological $\mathrm{pH}, \mathrm{Arg}_{9}$ and $\mathrm{Lys}_{9}$ show different associative behaviors with PG lipids ${ }^{[48]}$. Actually, Lys 9 peptides underwent electrostatic repulsion towards each other, resulting in an "anticooperative" association with anionic POPG, whereas $\operatorname{Arg}_{9}$ chains could aggregate at the POPG surface, a property ascribed to the better association of the guanidinium groups to the PG heads and to like-charge pairing made possible in guadinidium moieties compared to the ammonium side chains of Lys. Moreover, computer simulations carried out from $\mathrm{Arg}_{8}$ and $\mathrm{Lys}_{8}{ }^{[49]}$ suggest that Lys 8 may adopt a conformation prone to only associate with the PG headgroups, whereas $\mathrm{Arg}_{8}$ displays a "buried" conformation, also interacting with several side chains. Then, these works underline the complexity of the cationic peptide-anionic lipid association, which are not reducible to the electrostatic attraction, a feature illustrated by the similar electrochemical properties of the ferrocene-labelled peptides used in our study. The integrity of the DOPG bilayer remains unaffected by the association with the peptides (the CVs are recovered after several minutes of equilibration between the film and the solution), thus highlighting the very specific interaction of cationic peptides with DOPG compared to $\mathrm{Ru}\left(\mathrm{NH}_{3}\right)_{6}{ }^{3+}$.

Finally, the electrochemical features of ferrocene-tagged CPPs at DOPG modified electrodes appear to be independent on the "penetrating" nature of the peptides. Actually, the protein kinase $C$ inhibitor pKCi is commonly coined as non-cell penetrating peptide and is often used as a control-peptide in studies devoted to the internalization of CPPs. Unexpectedly, Fc-pKCi displays the most intense faradaic signature at DOPG-GCE, suggesting it may possess the most favorable partition coefficient between the DOPG film and the solution. The penetrating character of a peptide may in that case not be related to the magnitude of its association with the lipid. The electrochemical properties of the Fc- 
labelled peptides used in this work indifferently correspond to species both partitioning between the solution and the BLM and diffusing across the lipid film, preventing a discrimination between penetrating and non-penetrating peptides.

\section{Concluding remarks}

The behavior of small redox probes at DPhPC modified glassy carbon electrodes features a clear discrimination between ionic forms and neutral ones. Only neutral probes are allowed to penetrate the gel ordered bilayer of DPhPC, whereas charged probes are expelled from the lipid film. With anionic DOPG all probes display clear electrochemical responses in cyclic voltammetry. The cationic $\mathrm{Ru}\left(\mathrm{NH}_{3}\right)_{6}{ }^{3+}$ probe undergoes a strong electrostatic interaction with the anionic lipids which leads to the swelling and destructuration of the DOPG film. Apart from this specific electrostatic association, the DOPG film seems to allow access to the electrode surface for all probes, a property to be compared to the liquid disordered state of DOPG at ambient temperature. The CVs at DOPG-GCE are significantly different from the one observed at DPhPC and DMPC ${ }^{[35]}$ modified electrodes, which display unambiguous behavior towards the probes : neutral species accumulate in the lipid bilayer and exhibit symmetrical "thin layer" CVs while charged ions are blocked or expelled from gel phase phosphatidylcholine (PC) lipid films. The anionic and fluid phase DOPG shows more complex CVs with ferrocene-labelled peptides exhibiting a diffusional shape and an instability upon multiple cycling. The shape and magnitude of the peak currents at DOPG-GCE may therefore be linked to the weak and slow partition equilibrium of the peptides between the solution and the DOPG film.

\section{Acknowledgements}

The authors would like to thank Pr. Solange Lavielle and Dr. Gérard Chassaing for their constant support and encouragement along this work. We also wish to acknowledge the CNRS, SorbonneUniversité, École Normale Supérieure-PSL and French Agence Nationale de la Recherche (grant number: ANR-12-BS08-0002-01 “ELIPTIC") for their support. 
[1] M. P. Stewart, R. Langer, K. F. Jensen, Chem. Rev. 2018, 118, 7409-7531.

[2] N. J. Yang, M. J. Hinner, in Site-Specific Protein Labeling. Methods in molecular biology (Clifton, N.J.), Vol. 1266, Humana Press, New York, 2015, pp. 29-53.

[3] W. Shinoda, Biochim. Biophys. Acta, Biomembr. 2016, 1858, 2254-2265.

[4] B. Gupta, T. S. Levchenko, V. P. Torchilin, Adv. Drug Delivery Rev. 2005, 57, 637-651.

[5] C. Bechara, S. Sagan, FEBS Lett. 2013, 587, 1693-1702.

[6] P. F. Almeida, A. Pokorny, Biochemistry 2009, 48, 8083-8093.

[7] M. Di Pisa, G. Chassaing, J. M. Swiecicki, Biochemistry 2015, 54, 194-207.

[8] P. G. Dougherty, A. Sahni, D. Pei, Chem. Rev. 2019, 119, 10241-10287.

[9] A. Lamazière, O. Maniti, C. Wolf, O. Lambert, G. Chassaing, G. Trugnan, J. Ayala-Sanmartin, Biochim. Biophys. Acta, Biomembr. 2010, 1798, 2223-2230.

[10] X. Chen, F. Sa'adedin, B. Deme, P. Rao, J. Bradshaw, Biochim. Biophys. Acta, Biomembr. 2013, 1828, 1982-1988.

[11] P. Wadhwani, R. F. Epand, N. Heidenreich, J. Bürck, A. S. Ulrich, R. M. Epand, Biophys. J. 2012, 103, 265-274.

[12] F. Burlina, S. Sagan, G. Bolbach, G. Chassaing, Angew. Chem., Int. Ed. Engl. 2005, 44, 42444247.

[13] F. Burlina, S. Sagan, G. Bolbach, G. Chassaing, Nat. Protoc. 2006, 1, 200-205.

[14] S. Afonin, V. Kubyshkin, P. K. Mykhailiuk, I. V. Komarov, A. S. Ulrich, J. Phys. Chem. B 2017, 121, 6479-6491.

[15] J. P. Richard, K. Melikov, E. Vives, C. Ramos, B. Verbeure, M. J. Gait, L. V. Chernomordik, B. Lebleu, J. Biol. Chem. 2003, 278, 585-590.

[16] M. Di Pisa, J. M. Swiecicki, C. Mansuy, G. Chassaing, S. Lavielle, J. Pept. Sci. 2014, 20, S93-S94.

[17] J.-M. Swiecicki, M. Di Pisa, F. Burlina, P. Lecorche, C. Mansuy, G. Chassaing, S. Lavielle, Biopolymers (Peptide Science) 2015, 104, 533-543.

[18] F. G. Avci, B. Sariyar Akbulut, E. Ozkirimli, Biomolecules 2018, 8.

[19] M. J. Moreno, L. M. B. B. Estronca, W. L. C. Vaz, Biophys. J. 2006, 91, 873-881.

[20] R. de Oliveira, M. Durand, L. Challier, P. Messina, J. M. Swiecicki, M. Di Pisa, G. Chassaing, S. Lavielle, O. Buriez, E. Labbe, J. Electroanal. Chem. 2017, 788, 225-231.

[21] P. Messina, F. Lemaitre, F. Huet, K. A. Ngo, V. Vivier, E. Labbé, O. Buriez, C. Amatore, Angew. Chem., Int. Ed. Engl. 2014, 53, 3192-3196.

[22] S. Piantavigna, G. McCubbin, S. Boehnke, B. Graham, L. Spiccia, L. Martin, Biochim. Biophys. Acta, Biomembr. 2011, 1808, 1811-1817.

[23] M. Abdelhamid, S. Piantavigna, A. Bond, B. Graham, L. Spiccia, L. Martin, A. O'Mullane, Electrochem. Commun. 2015, 51, 11-14.

[24] P. Messina, G. Hallais, E. Labbé, M. Beranger, G. Chassaing, S. Lavielle, C. Mansuy, O. Buriez, C. Amatore, Electrochim. Acta 2012, 80, 180-186.

[25] O. Buriez, L. M. Moretto, P. Ugo, Electrochim. Acta 2006, 52, 958-964.

[26] A. I. P. Jimenez, L. Challier, M. Di Pisa, M. Guille-Collignon, F. Lemaître, S. Lavielle, C. Mansuy, C. Amatore, E. Labbé, O. Buriez, Electrochem. Commun. 2015, 54, 41-45.

[27] W. C. Hung, F. Y. Chen, H. W. Huang, Biochim. Biophys. Acta, Biomembr. 2000, 1467, 198206.

[28] R. Koynova, B. Tenchov, in Encyclopedia of Biophysics (Ed.: G. C. K. Roberts), Springer Berlin Heidelberg, Berlin, Heidelberg, 2013, pp. 1841-1854.

[29] J.-M. Swiecicki, A. Bartsch, J. Tailhades, M. Di Pisa, B. Heller, G. Chassaing, C. Mansuy, F. Burlina, S. Lavielle, ChemBioChem 2014, 15, 884-891.

[30] X. H. Liu, W. M. Huang, E. K. Wang, J. Electroanal. Chem. 2005, 577, 349-354. 
[31] Z. Wu, J. Tang, Z. Cheng, X. Yang, E. Wang, Anal. Chem. 2000, 72, 6030-6033.

[32] Y. Yi, G. Weinberg, M. Prenzel, M. Greiner, S. Heumann, S. Becker, R. Schlögl, Catal. Today 2017, 295, 32-40.

[33] M. Santhiago, C. M. Maroneze, C. C. C. Silva, M. N. L. Camargo, L. T. Kubota, ChemElectroChem 2015, 2, 761-767.

[34] R. L. McCreery, Chem. Rev. 2008, 108, 2646-2687.

[35] O. Mertins, P. Messina, E. Labbé, V. Vivier, S. Arbault, F. Lemaitre, O. Buriez, C. Amatore, Inorg. Chim. Acta 2011, 374, 59-68.

[36] B. Hirschorn, M. E. Orazem, B. Tribollet, V. Vivier, I. Frateur, M. Musiani, Electrochim. Acta 2010, 55, 6218-6227.

[37] R. Fettiplace, D. M. Andrews, D. A. Haydon, J. Membr. Biol. 1971, 5, 277-+.

[38] T. Kondo, T. Kanai, K. Uosaki, Langmuir 2001, 17, 6317-6324.

[39] S. Turkyilmaz, W.-H. Chen, H. Mitomo, S. L. Regen, J. Am. Chem. Soc. 2009, 131, 5068-+.

[40] A. Odinokov, D. Ostroumov, J. Phys. Chem. B 2015, 119, 15006-15013.

[41] P. Seeman, W. O. Kwant, T. Sauks, W. Argent, Biochim. Biophys. Acta 1969, 183, 490-\&.

[42] J. H. Kim, S.-Y. Yim, M.-K. Oh, M. D. Phan, K. Shin, Soft Matter 2012, 8, 6504-6511.

[43] P. Bertoncello, P. Ugo, J. Braz. Chem. Soc. 2003, 14, 517-522.

[44] P. Ugo, P. Bertoncello, F. Vezzà, Electrochim. Acta 2004, 49, 3785-3793.

[45] L. M. Moretto, T. Kohls, A. Chovin, N. Sojic, P. Ugo, Langmuir 2008, 24, 6367-6374.

[46] H. Girault, Analytical and Physical Electrochemistry, EFPL Press 2004, 2004.

[47] C. Batchelor-McAuley, R. G. Compton, J. Phys. Chem. C 2014, 118, 30034-30038.

[48] A. D. Robison, S. Sun, M. F. Poyton, G. A. Johnson, J.-P. Pellois, P. Jungwirth, M. Vazdar, P. S. Cremer, J. Phys. Chem. B 2016, 120, 9287-9296.

[49] A. C. McGeachy, E. R. Caudill, D. Liang, Q. Cui, J. A. Pedersen, F. M. Geiger, Chem. Sci. 2018, 9, 4285-4298. 


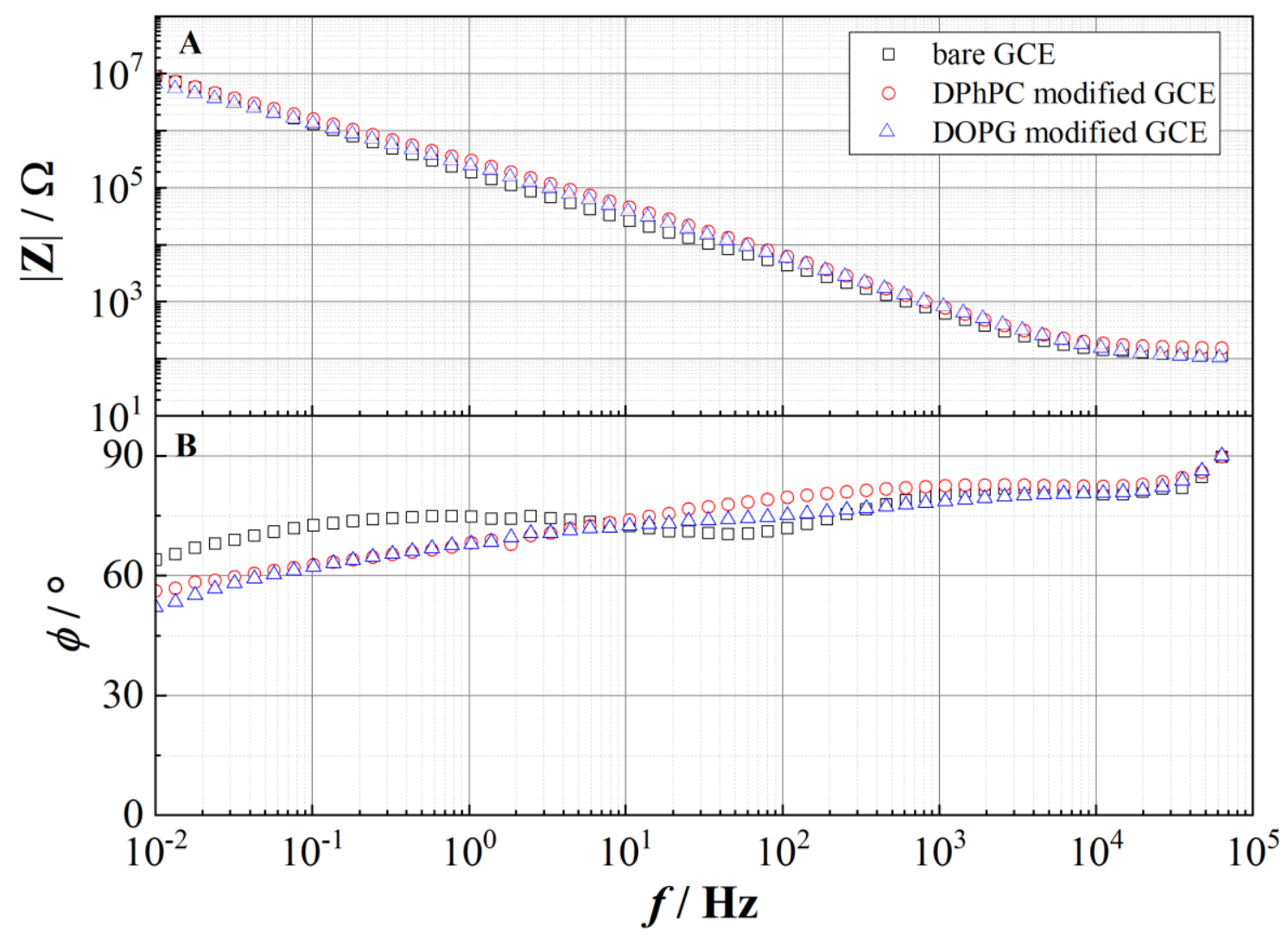

Figure SI: Bode plots of bare C electrode (A), and DPhPC (B) and DOPG (C) modified GCE in aqueous $0.1 \mathrm{M} \mathrm{NaCl}$. Applied potential $0.25 \mathrm{~V} \mathrm{vs.} \mathrm{Ag} / \mathrm{AgCl}$ (perturbation $10 \mathrm{mV}_{\mathrm{rms}}$ ) 